\title{
New imaging techniques for diagnosing coronary artery disease
}

\author{
Esteban Escolar, Guy Weigold, Anthon Fuisz, Neil J. Weissman
}

\section{ABSTRACT}

New tomographic cardiovascular imaging tests, such as intravascular ultrasonography (IVUS), coronary computed tomography (CT) angiography and magnetic resonance imaging (MRI), can be used to assess atherosclerotic plaques for the characterization and early staging of coronary artery disease (CAD). Although IVUS images have very high resolution capable of revealing very early preclinical CAD, it is an invasive technique used clinically only in conjunction with a coronary intervention. Multiple-slice coronary CT angiography, which is noninvasive, shows promise as a diagnostic method for CAD. New 64-slice cardiac CT technology has high accuracy for the detection of lesions obstructing more than $50 \%$ of the lumen, with sensitivity, specificity, and positive and negative predictive values all better than $90 \%$ in patients without known CAD. Cardiac MRI is also improving accuracy in coronary plaque detection and offers a better opportunity for plaque characterization. With further advances in tomographic imaging of coronary atheromas, the goal will be to detect plaques earlier in the development of CAD and to characterize the plaques most likely to generate a clinical event.

CMAJ 2006;174(4):487-95

I nvasive coronary angiography is the standard clinical means for depicting the coronary arteries and is the "gold standard" for diagnosing coronary artery disease (CAD). Since its implementation over 30 years ago, more than 2 million coronary angiograms have been made yearly in North America. Coronary angiography requires high-level technical expertise and technology, which makes it relatively expensive and limits it to a select population. Angiography also has its limitations, since only the lumen is displayed ("luminology") and the information it provides about the in coronary plaque is not extensive. However, new tomographic methods for cardiovascular imaging such as intravascular ultrasonography (IVUS), coronary CT angiography and MRI can assess the atherosclerotic plaques responsible for early, "silent" CAD. In this article, we review the current and potential future clinical applications of these 3 tools for the visual detection of atherosclerotic CAD.

\section{Intravascular ultrasonography}

IVUS has become a powerful complementary tool to measure and characterize coronary vessels and atherosclerotic plaques. An invasive procedure, IVUS produces images with a small ultrasound transducer mounted on a catheter similar to the standard catheters employed in coronary angioplasty. The catheter is advanced over the wire inside the coronary artery until it reaches a position distal to the segment to be studied. A series of tomographic images of the coronary artery are obtained as the catheter is slowly pulled back. Each IVUS image displays a $360^{\circ}$ cross-sectional view of the layers of the coronary artery (intima, media and adventitia) as well as the lumen (Fig. IA,B). Modern devices can perform 3-dimensional reconstructions online that provide information about the length, volume and reference landmarks of a plaque.

Standard radiographic coronary angiography provides a single-plane "shadow" of the vascular lumen; its ability to accurately and reproducibly measure the degree of stenosis and to characterize plaque morphology is limited. ${ }^{1-3}$ Extensive experience in our and other centres has shown that IVUS is a safe, accurate and reproducible alternative method for assessing the severity and morphology of lesions. ${ }^{4,5}$ The types of plaques detectable by IVUS are summarized in Box I.

\section{Clinical use}

The best-studied clinical application of IVUS is in the placement of stents into coronary vessels (Fig. IC,D, Fig. 2, Fig. 3). Stenting has revolutionized the treatment of atherosclerotic CAD. Restenosis inside the stent, which occurs in $5 \%-20 \%$ of cases (depending on the complexity of the lesion and underlying risk factors), nevertheless remains a major shortcoming. IVUS has played an important role in the understanding of stent failures.

In-stent restenosis is typically caused by neointimal hyperplasia: new fibrotic tissue that grows inside the stent and obstructs the lumen. Serial IVUS studies performed in cases of bare-metal stent failure have shown that underexpansion of the stent is an important cause of early failure. ${ }^{6}$ If the stent is poorly expanded, small amounts of neointimal hyperplasia will occlude the vessel. ${ }^{7,8}$ Although use of a drug-eluting stent reduces the risk of in-stent stenosis by two-thirds or even three-quarters, recent evidence suggests that stent under- 
Box 1: Types of plaques and other lesions reliably revealed by intravascular ultrasonography (IVUS)

- Soft plaque is composed mainly of echolucent tissue (i.e., tissue with low echogenicity) containing minimal calcium, collagen or elastin. Echolucent plaque correlates with a high lipid content and necrotic tissue, and can represent hemorrhage and thrombi.

- Fibrous plaque, with its intermediate level of echogenicity, represents the majority of atherosclerotic lesions.

- Calcific plaque is highly echogenic, with an acoustic shadow. Most of its content is calcium. (Highly fibrotic plaques occasionally can show echo features similar to those of calcic plaques.)

- Mixed plaque is a combination of any of the preceding acoustic subtypes.

Examples of other structures and tissues that can be brought into view with IVUS include:

- Intraluminal thrombus, usually seen as a mass in the lumen

- Intimal hyperplasia, which appears as very mildly echogenic tissue within a stent (Figs. 1-3)

expansion remains the principal cause of thrombosis associated with a drug-eluting stent and the higher rate of revascularization of stented lesions. ${ }^{9,10}$

Images obtained by IVUS before stent placement therefore provide useful information on the precise length of the lesion to be covered and the size of the stent needed (Table I). After placement of the stent, IVUS helps to optimize the final result and maximize the area it covers, which probably minimizes the risk of restenosis. The lessons learned from these IVUS observations have changed the way that stents are currently deployed and thereby reduced both patients' risk of angiography and the costs associated with drug-eluting stents.

During the bare-metal stent era, several reports were published on the benefit of IVUS-guided versus angiographyguided angioplasty; 3 prospective, randomized controlled trials ${ }^{11-14}$ deserve specific mention. They showed, with different degrees of statistical power, that the lumen dimensions of patients whose stenting was IVUS-guided were better at follow-up, with some reduction in restenosis and targetlesion revascularization at later visits (Table 2).

In our centre, IVUS is used extensively for diagnosis and to guide stenting. It is specifically used in the evaluation of left main lesions, bifurcations, complex lesions and hazy lesions (those with ambiguous angiography). When stenting is imminent, the vascular segment to be treated is scanned with IVUS and the procedure planned on the basis of findings for lesion and vessel size, length and location. The final result is checked with the same IVUS catheter to ensure optimal stent deployment - expansion, apposition and identification of potential complications.

\section{Future applications}

Conventional angiography shows the presence or absence of atherosclerotic plaques; IVUS, however, also offers indications of potential plaque formation by means of information on the character of the coronary vessels. For example, in the early stages of coronary atherosclerosis, remodelling of the vessel occurs such that enlargement of the adventitium prevents the atheroma from encroaching on the lumen, which leaves lumen size unchanged and appearing normal on conventional angiographic images. ${ }^{15}$ IVUS, like MRI and CT, can reveal arterial remodelling, to allow the detection of atherosclerosis at an earlier stage.

Early detection of atherosclerotic plaques is relevant because most patients with acute coronary syndromes have minimal or mild coronary lumen obstruction detected by angiography. ${ }^{16,17}$ It is known that these lesions may suddenly rupture, which exposes their highly thrombogenic lipid core, causes luminal thrombosis and engenders the clinical picture of acute coronary syndromes. One of the features of these unstable, vulnerable plaques is a thin, fibrous cap; increased macrophage infiltration within the cap can cause proteolytic enzymes to be expressed, which will weaken the fibrous cap and ultimately promote plaque disruption. ${ }^{18}$

IVUS does not as yet have the resolution necessary to identify this thin fibrous cap; however, optical coherence tomography (OCT), an optical equivalent of intravascular ultrasonography, provides high-resolution ( $>$ Io $\mu \mathrm{m}$ ) tomographic intra-arterial images (Fig. 4). Recently, with use of this new technology, a higher prevalence of thin capping plaques was found to occur among patients with acute coronary syndromes than among those with stable CAD. ${ }^{19}$ The identification of patients likely to have acute coronary syndromes (through identification of a vulnerable plaque) is one of the most intense areas of cardiovascular research. The increase in spatial resolution that characterizes OCT may further our understanding of $\mathrm{CAD}$ and may lead to earlier detection and better methods of primary prevention.

IVUS has also been used as a research tool to measure subtle changes in plaque volume that were undetectable by conventional angiography. ${ }^{20}$ In future trials, changes in plaque volume may be important secondary end points with which to correlate clinical outcomes.

\section{Multiple-slice spiral computed tomography}

Cardiac CT has recently emerged as a new alternative to invasive angiography. With the rapid technological advances in multiple-slice spiral computed tomography (MSCT), it is now possible to reveal coronary vessels and bypass grafts noninvasively.

One of the difficulties in imaging coronary vessels is that the heart is in constant motion. The current speed of CT scanners, increased resolution and the ability to time the scan to match the cardiac cycle by means of electrocardiography all help to minimize cardiac-motion artifacts and allow for the analysis of cardiac anatomy. However, the "thinner" slices required are more susceptible to noise; therefore, scans of patients whose body mass index is greater than 40 are unfortunately almost always nondiagnostic. MSCT coronary angiography is performed during the administration of intravenous 
contrast. The scan is completed in Io-I5 seconds, an easy length of time for the subject to hold his or her breath. Despite coordination of image acquisition by means of electrocardiography, making a coherent composite image of the moving heart is still challenging. The best image quality is obtained when the heart rate is slower than $6_{5}$ beats/min and the cardiac rhythm is regular.

MSCT also allows the evaluation of cardiac function. With reconstruction of multiple slices of the short axis of the ventricle at ro instances evenly distributed across the cardiac cycle, left- and right-ventricular function can both be analyzed. Quantitative estimations of ventricular function by MSCT have demonstrated good accuracy, with calculated ejection fractions within 10\% of those obtained by means of MRI, ${ }^{21,22}$ which is considered the most accurate method. Moreover, MSCT also detects abnormalities in wall motion. Supportive findings of contrast hypodensity and myocardial thinning in the area of an infarct make it a good tool for detecting myocardial infarcts. Finally, in addition to details on cardiac anatomy, MSCT also provides highly detailed information about the aorta, pulmonary artery and veins, lungs and mediastinum.

\section{Clinical use}

Several investigations ${ }^{23-30}$ have been made on the accuracy of MSCT angiography in cases of known or suspected CAD. Although these studies had some differences in methodology and patient characteristics, all compared rates of detection of coronary lumen obstruction $>50 \%$ with MSCT and with invasive angiography; examined patients already medicated with $\beta$-blockers; excluded those who had cardiac arrhythmias; and reported analyses of sensitivity, specificity, and positive and negative predictive values. Findings for sensitivity ranged from $82 \%$ to $100 \%$; specificity, $78 \%$ to $98 \%$. The real strength of cardiac CT was found to be its negative predictive value, which in the most recent studies ranged from $95 \%$ to $97 \%$ among patients deemed to be at intermediate-to-high risk of CAD (Table 3; additional data are available online at www.cmaj.ca/cgi/content/full/I74 /4/487/DCI).

A recurring theme of these studies is that heavily calcified segments are often either unevaluable or prone to misdiagnosis. Recently, 2 studies $^{27,30}$ evaluated the accuracy of 64slice MSCT angiography in the detection of coronary stenoses in patients with no known CAD. They both found sensitivity, specificity, and positive and negative predictive values of better than 90\% (Fig. 5).
MSCT angiography also portrays coronary-artery bypass grafts (CABG) well; the main body of the conduits can be evaluated for graft stenosis with good accuracy. ${ }^{31,32}$ Making distal anastomoses visible can be problematic, however, if metal clips are present at the anastomotic site. Native vessels are also often difficult to assess because of diffuse vessel calcification, which obscures the underlying lumen. It remains to be seen whether cardiac CT can reliably evaluate patients with these attributes. Similarly, stent evaluation can sometimes be limited; best results occur with stents at least $3.0 \mathrm{~mm}$ in diameter that are located in proximal segments. On the other hand, cardiac CT is an excellent means to evaluate CABG patients before a repeat sternotomy, to
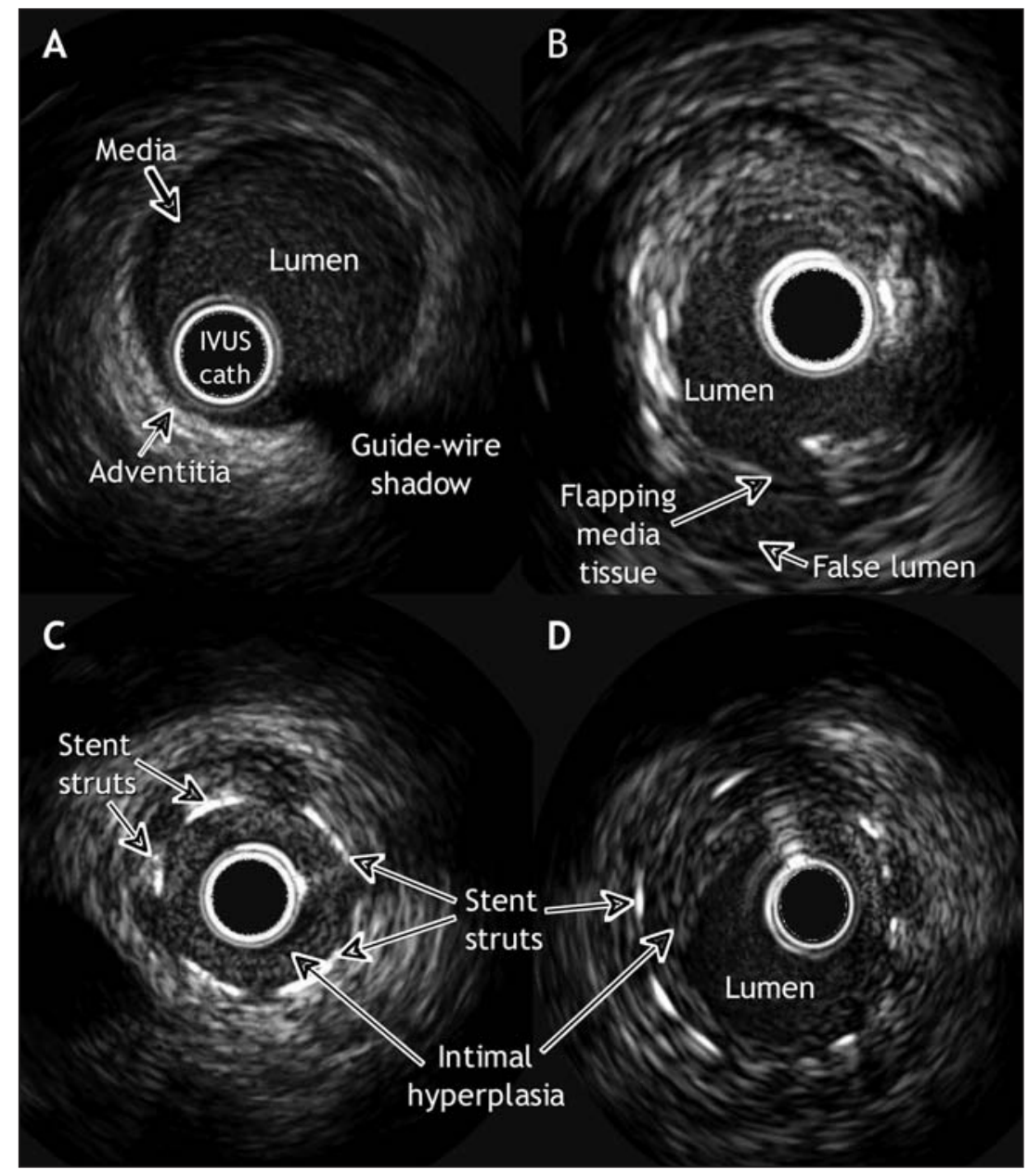

Fig. 1. Images of coronary arteries, revealed with intravascular ultrasonography (IVUS). A: A normal artery. The layers of the arterial wall, from innermost to outermost, are the intima, media and adventitia. The intima is an endothelial cell layer where atheroma accumulates; the external boundary of this layer is the internal elastic membrane. The media, composed of smooth muscle cells, elastin and collagen, is encircled by the external elastic membrane. The adventitia is mainly composed of fibrous tissue. In young people free of atherosclerotic disease, the 3 layers are difficult to see as separate structures because the media and intima are smaller than the resolution of IVUS $(<100 \mu \mathrm{m})$. B: Mixed plaque (fibrotic and calcific) with a dissection of the media at the " 6 o'clock" position. C: In-stent restenosis occluding the lumen. $\mathbf{D}$ : In-stent restenosis without angiographically significant occlusion. 
detect a graft that has become adherent to the midline sternum. The anatomic detail evinced by cardiac CT allows surgeons to plan the procedure precisely, so that surgical trauma to the graft or other cardiovascular structures is avoided (Fig. 6). ${ }^{33}$

In our centre, MSCT angiography is used to rule out CAD in patients at low or intermediate risk of it, and to evaluate patients with a prior CABG who are scheduled for a new revascularization procedure. This clinical service has become a routine part of our support to the cardiology community; we carry out several MSCT scans each day.

\section{Future applications}

Future directions for clinical use of cardiac CT include rapid triage in the emergency department of patients with chest pain; guidance for the placement of biventricular pacemaker leads and percutaneous coronary intervention in people with chronic total vascular occlusions; and, in newly diagnosed cases of cardiomyopathy, discrimination of ischemic from nonischemic causes.

Because there is evidence suggesting that the amount of calcium in the coronary vessels predicts future events, methods to measure calcium in asymptomatic patients to gauge their risk of coronary-artery events have been the focus of research interest. The CT imaging protocol differs from that for conventional angiography: it exposes the patient to much less radiation, is performed without intravenous contrast and is widely available.

Although younger patients with acute coronary events rarely exhibit coronary calcification, ${ }^{34,35}$ calcium is a frequent feature of coronary arteries and is found in $70 \%-80 \%$ of the population. ${ }^{36}$ Atherosclerotic plaques commonly contain calcium, whereas the eroded or ruptured plaques that largely are responsible for acute coronary syndromes rarely do. Therefore, a high calcium score is a marker of a large burden of coronary plaque, only some of which is calcified. It is most likely the noncalcified coexistent plaque that is responsible for the increased frequency of events in these people. This supports the idea of a diffuse unstable disease instead of the previously accepted concept of focal vulnerable plaque. ${ }^{37,38} \mathrm{~A}$ recent study ${ }^{39}$ investigated calcium scores among more than Io ooo asymptomatic people; the degree of coronary calicification was estimated by means of electron-beam CT scanning. After a mean follow-up period of 5 years, the death rate was $2.4 \%$. In a risk-adjusted model, coronary calcium was found to be an independent predictor of mortality $(p<0.00 \mathrm{I})$. Adjusted relative risks for death varied directly with increas-

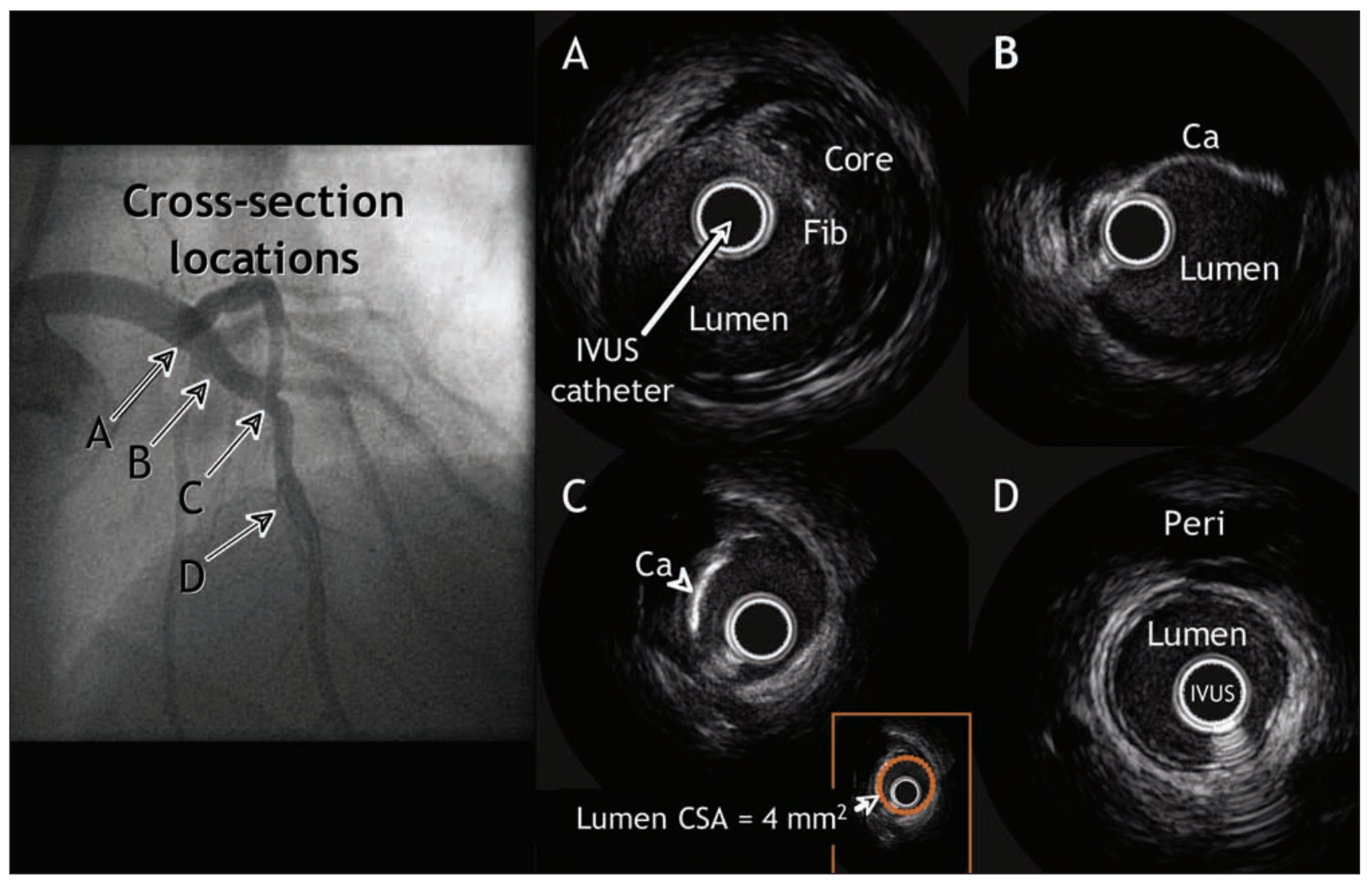

Fig. 2: The upper-left panel is a coronary angiographic image of clinically nonsignificant obstructive disease of the left anterior descending artery. Lettered arrows identify the locations of 4 IVUS cross-sections, as follows. A: In an area that appeared normal with angiography, a nonobstructive plaque is revealed containing a necrotic or lipid core covered by more echogenic tissue (Fib). B: In a section that likewise appeared normal with angiography, a calcified plaque can be seen. C: A severely calcified plaque with a minimum lumen crosssectional area (CSA) of $4 \mathrm{~mm}^{2}$ (see inset). D: An IVUS cross-section showing a normal distal reference, the pericardium (Peri). 
ing calcium scores; the relative risk of death at 5 years for the highest category (calcium scores > Iooo) was 4.03 (95\% confidence interval $[\mathrm{CI}] 2.52-6.40$ ) compared with the lowest category (scores < I0). A recent prospective, populationbased study ${ }^{40}$ involving 4903 patients $40-70$ years of age with no symptoms of CAD showed that coronary calcium scoring obtained with electron-beam CT scanning predicted cardiovascular events independently of traditional risk factors. The relative risk for all CAD-related events among subjects with calcium scores higher than Ioo was 9.6 (95\% CI 6.7-I3.9) compared with those who had lower scores.

The CT calcium score is still experimental. However, it is a noninvasive tool that promises to be valuable in stratifying risk of CAD among asymptomatic patients, especially those at low or intermediate risk of events according to traditional risk factors. ${ }^{41,42}$

In conclusion, these statements can be made about this exciting area:

I. Cardiac CT is a safe and reliable procedure.

2. Heart-rate modulation with $\beta$-blockade is required to consistently obtain high-quality diagnostic images.

3. Cardiac CT scans can be used to accurately identify and to exclude significant CAD, especially in vessels without heavy calcification that are $\mathrm{I} .5 \mathrm{~mm}$ or more in diameter.
4. Its high negative predictive value makes cardiac CT a fast and reliable means of evaluating chest pain or suspected false-positive results of stress tests in patients with a low or intermediate likelihood of clinically significant CAD.

5. Calcium scores can predict risk of death from CAD.

6. We will likely see expanded indications for use of MSCT angiography, to include the evaluation of chest pain in the emergency department, the study of coronary anatomy before percutaneous coronary intervention or device implantation, and the noninvasive discrimination of ischemic from nonischemic cardiomyopathy.

\section{Cardiovascular MRI}

Coronary magnetic resonance angiography (MRA) makes the noninvasive depiction of major epicardial coronary arteries possible in most subjects without the injection of contrast medium and exposure of the patient to radiation. Since the first report in 1987 , technological advances in coronary MRA have led to enhanced spatial resolution and the possibility of imaging while the patient is breathing freely. ${ }^{43}$ However, due to breathing and cardiac motion, tortuosity and small vessels, coronary MRA is still technically difficult for the confident determination of the presence as well as the severity of coronary

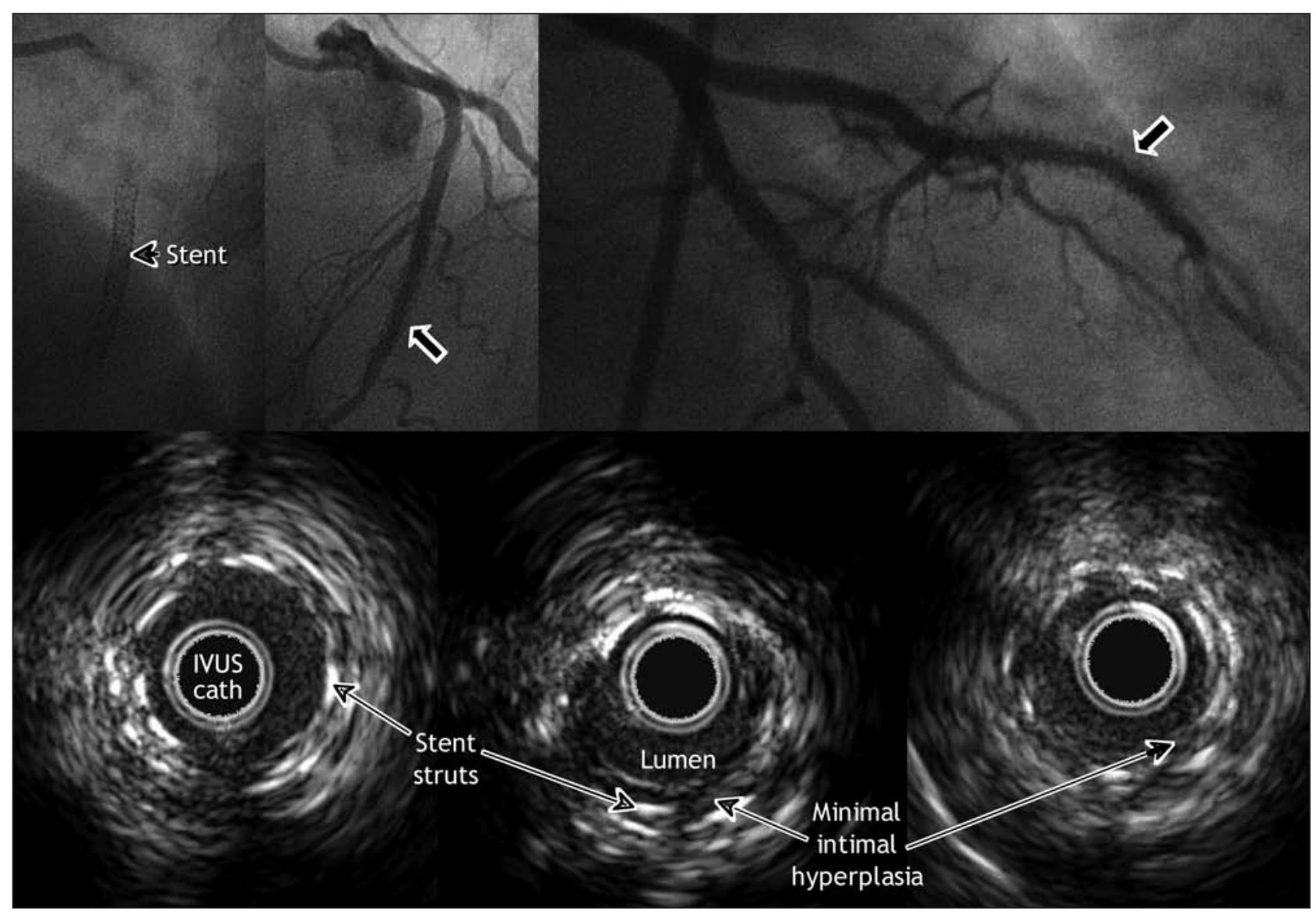

Fig. 3: Three months after insertion of a drug-eluting stent for in-stent restenosis in the middle segment of the left anterior descending artery, this patient was readmitted to hospital because of angina. Angiography showed a hazy lesion within the stent. IVUS imaging, however, did not reveal any notable intimal hyperplasia. 
stenosis. Great improvement was achieved during the last 5 years with the new generation of magnetic resonance platforms. Current coronary MRA sequences have resolution on the order of 500-700 $\mu \mathrm{m}$ and are approaching the resolution of the x-ray arteriogram. Present techniques involve the acquisition of 3 -dimensional data sets that contain the artery during free breathing, with the use of navigator sequences to account for heart motion. The image is acquired during a brief moment (about $0.08 \mathrm{~s}$ ) that the heart is stationary during the cardiac cycle. These individual acquisitions are then added together to produce the final image. Total acquisition can take up to ro minutes. If the goal is to examine all the main coronary arteries, at least 4 acquisitions will be needed.

\section{Clinical use}

Coronary MRA is currently used much less frequently than MSCT angiography to detect CAD. Images obtained with coronary MRA provide a measure of stenosis, wall thickening and possibly composition of the plaque (Fig. 7). Coronary MRA captures images by detecting protons in moving blood every few milliseconds as they travel through an arbitrary region in space. Protons are "tagged" as blood flows through the coronary vessels, which allows the acquisition of consecutive movie frames as the heart pushes blood through the vascular bed. Body tissue surrounding the moving blood is never excited and therefore remains invisible. ${ }^{44}$

Table 1: Indications, resolution and major risks of 3 vascular imaging modalities

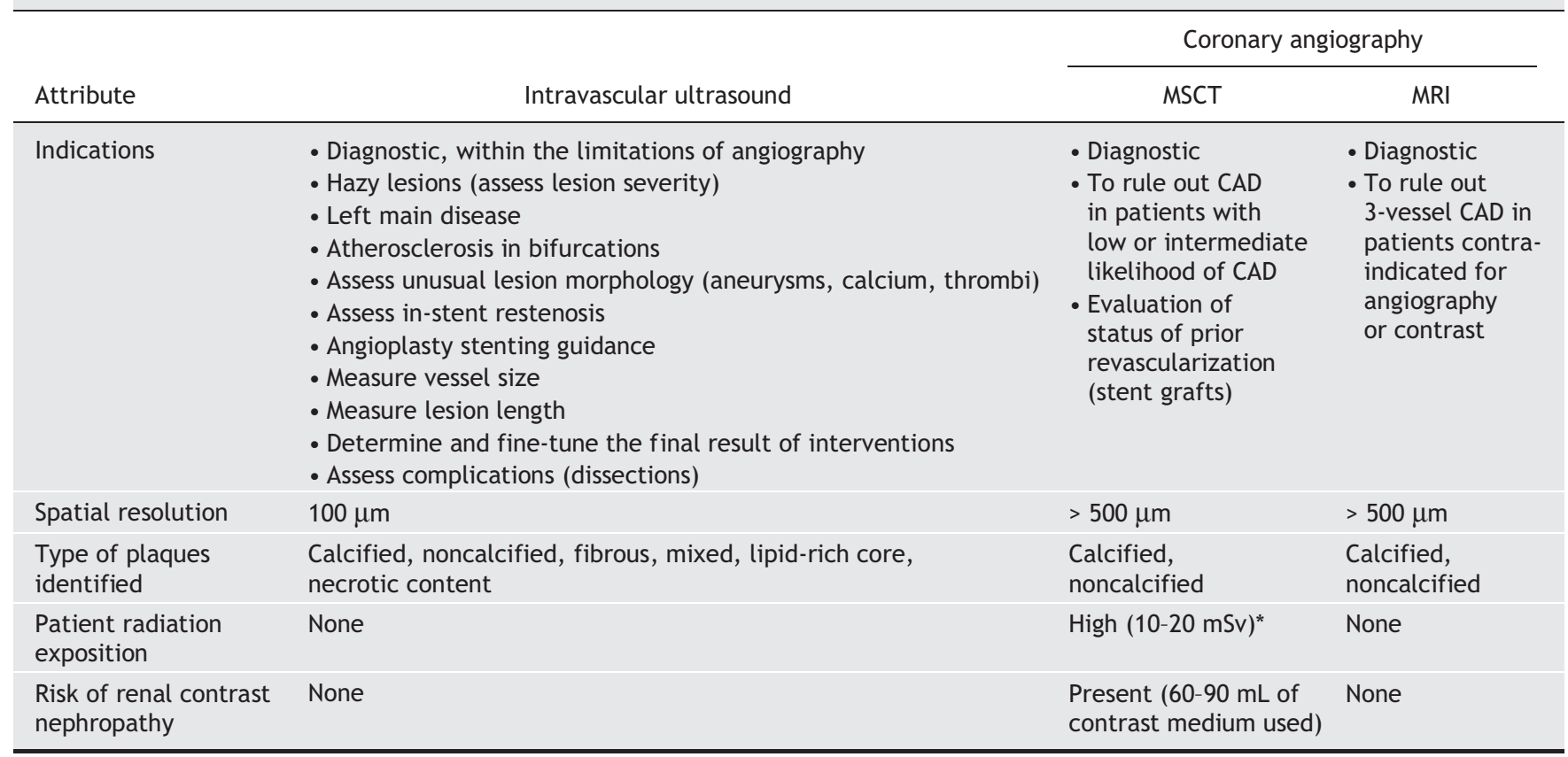

Note: MSCT = multiple-slice spiral computed tomography, $M R I=$ magnetic resonance imaging, $C A D=$ coronary-artery disease.

*Could be reduced by dose-modulation technology.

Table 2: Summary of randomized controlled trials comparing placement of coronary stents guided by intravascular ultrasound (IVUS) with placement guided by conventional angiography

\begin{tabular}{|c|c|c|c|}
\hline Study & End point & $\begin{array}{c}\text { Results, IVUS } \\
\text { v. conventional }\end{array}$ & Comment \\
\hline $\begin{array}{l}\text { RESIST } \\
\text { Schiele et al } 1998,{ }^{11} 2000^{12} \\
n=155\end{array}$ & $\begin{array}{l}\text { Angiographic } \\
\text { restenosis by } \\
6 \text { mo }\end{array}$ & $\begin{array}{l}28.8 \% \text { v. } 22.5 \% \\
p=0.25\end{array}$ & $\begin{array}{l}\text { At } 18 \text {-mo clinical follow-up, rate of MACE was higher in angiography } \\
\text { than in IVUS group ( } 37 \% \mathrm{v} \text {. } 25 \% \text {, OR } 1.7,95 \% \text { confidence interval } \\
0.82-3.63) \text {, which did not reach statistical significance }\end{array}$ \\
\hline $\begin{array}{l}\text { OPTICUS } \\
\text { Mudra et al } 2001^{13} \\
n=550\end{array}$ & $\begin{array}{l}\text { Angiographic } \\
\text { restenosis by } \\
6 \mathrm{mo}\end{array}$ & $\begin{array}{l}24.5 \% \text { v. } 22.8 \% \\
p=0.68\end{array}$ & $\begin{array}{l}\text { At } 6 \text { and } 12 \text { mo, no benefit in angiographic or clinical parameters } \\
\text { was shown for IVUS-guided angioplasty }\end{array}$ \\
\hline
\end{tabular}

Note: RESIST = REStenosis after Intravascular ultrasound Stenting study, MACE = major adverse cardiac event (including death, myocardial infarction, target lesion revascularization), OPTICUS = OPTImal Coronary UltraSound trial, TULIP = transurethral ultrasound-guided laser-induced prostatectomy, TLR = target lesion revascularization. 
This produces a "virtual angiogram" from the magnetic resonance scan.

There is limited evidence for using coronary MRA to diagnose atherosclerosis, but a multicentre trial involving rog patients, with a methodology similar to that already described for comparing CT angiography studies with invasive coronary angiography (the "gold standard"), reported a sensitivity of $93 \%$, specificity $42 \%$, positive predictive value $42 \%$ and negative predictive value $8 \mathrm{I} \%$ for CT angiography. When only left main or 3-vessel disease was analyzed, these values improved to 100\%, 85\%, 54\% and 100\%, respectively. ${ }^{45}$ Reasonable accuracy was achieved with the use of technology that has become easily available.

Other areas that have been investigated include the use of intravascular gadolinium-based agents and 3-dimensional acquisition strategies. The most promising technique currently seems to be whole-heart type acquisition, in which the entire heart is scanned in a fashion similar to cardiac CT protocols. The resulting 3-dimensional data set can be reformatted in any orientation desired, again taking a page from the success of cardiac CT techniques.

At present, our institution uses cardiac MRI for analysis of structure, function and anatomy of the heart and great vessels. Although we do not routinely use it for direct imaging of coronary arteries (other than investigationally or in special clinical situations), we do routinely perform perfusion tests and viability testing to help guide management of CAD.

\section{Future applications}

Future research should examine the multipurpose capabilities of the magnetic resonance scanner and combining perfusion and wall-motion assessments (the strengths of cardiac MRI)

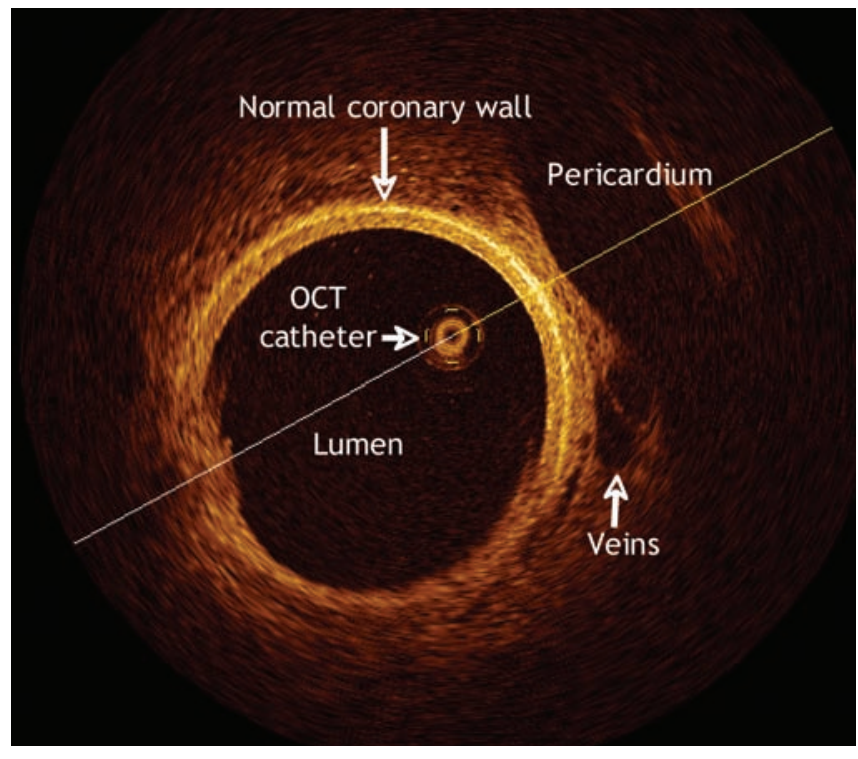

Fig. 4: Optical coherence tomographic (OCT) scan of a pig's normal coronary artery. The high resolution of the image is apparent, particularly in the details of the pericardium, veins and the coronary-artery walls.
Table 3: Summary of clinical trials evaluating the accuracy of multiple-slice spiral computed tomographic angiography

\begin{tabular}{|c|c|c|c|c|c|}
\hline Study report & $\begin{array}{l}\text { Subjects' } \\
\text { risk of CAD }\end{array}$ & PPV & NPV & $\begin{array}{l}\text { Sensi- } \\
\text { tivity }\end{array}$ & $\begin{array}{l}\text { Speci- } \\
\text { ficity }\end{array}$ \\
\hline Nieman $2002^{23}$ & High & 80 & 97 & 95 & 86 \\
\hline Ropers $2003^{24}$ & High & 81 & 82 & 85 & 78 \\
\hline Hoffmann $2004^{25}$ & High & 90 & 75 & 86 & 82 \\
\hline Hoffmann $2005^{26}$ & Mod-high & 90 & 95 & 97 & 87 \\
\hline Kuettner $2005^{27}$ & High & 87 & 97 & 82 & 98 \\
\hline Leschka $2005^{28}$ & Mod-high & 87 & 99 & 94 & 97 \\
\hline Mollet $2005^{29}$ & Low-mod & 91 & 100 & 100 & 85 \\
\hline Raff $2005^{30}$ & Mod-high & 93 & 93 & 90 & 95 \\
\hline
\end{tabular}

Note: $\mathrm{CAD}=$ coronary-artery disease, $\mathrm{PPV}=$ positive predictive value, NPV = negative predictive value, $\bmod =$ moderate .

with the imaging of coronary arteries. By detecting an abnormality in wall motion or a perfusion defect and then imaging the artery that is likely at fault, with MRI it may be possible to improve the accuracy of CAD diagnosis beyond any technique now available.

Because of the physics of magnetic resonance, it is possible to design contrast media that can be targeted with specific markers. For example, Spuentrup and colleagues ${ }^{46}$ used a fibrin-targeted contrast medium to identify coronary and pulmonary thrombi. The final images show coronary lumens or pulmonary arteries with white enhancements at the locations of thrombi. The clinical and research implications of this and other markers that are in development are promising a pivotal role for them in clinical molecular imaging in future. For example, vulnerable plaques could be identified with markers that attach to the neovascularization or to macrophages in inflamed plaques.

Magnetic resonance-based molecular imaging is a science in its infancy. The development of targeted, "smart" contrast agents is ongoing, and clinical trials to test them have just begun. ${ }^{47}$

\section{Conclusion}

Tomographic imaging of the coronary arteries, whether with IVUS, CT or MRI, provides more information about atherosclerotic lesions than can traditional angiography, and allows deeper insights into the mechanism and the diagnostic and therapeutic implications of new strategies to treat CAD. At present, the clinical indications for coronary stent placement or bypass surgery are decided according to the evidence from clinical trials that used conventional coronary angiography. As technology now allows us to obtain more anatomic detail in views of vessels and atherosclerotic plaques, these imaging modalities must be incorporated into future studies and clinical decision schemes. It is hoped that the ability to characterize plaques, not simply to detect them, will allow the identification of those patients who are at greatest risk for coronary events and facilitate the selection and tailoring of interventions. 


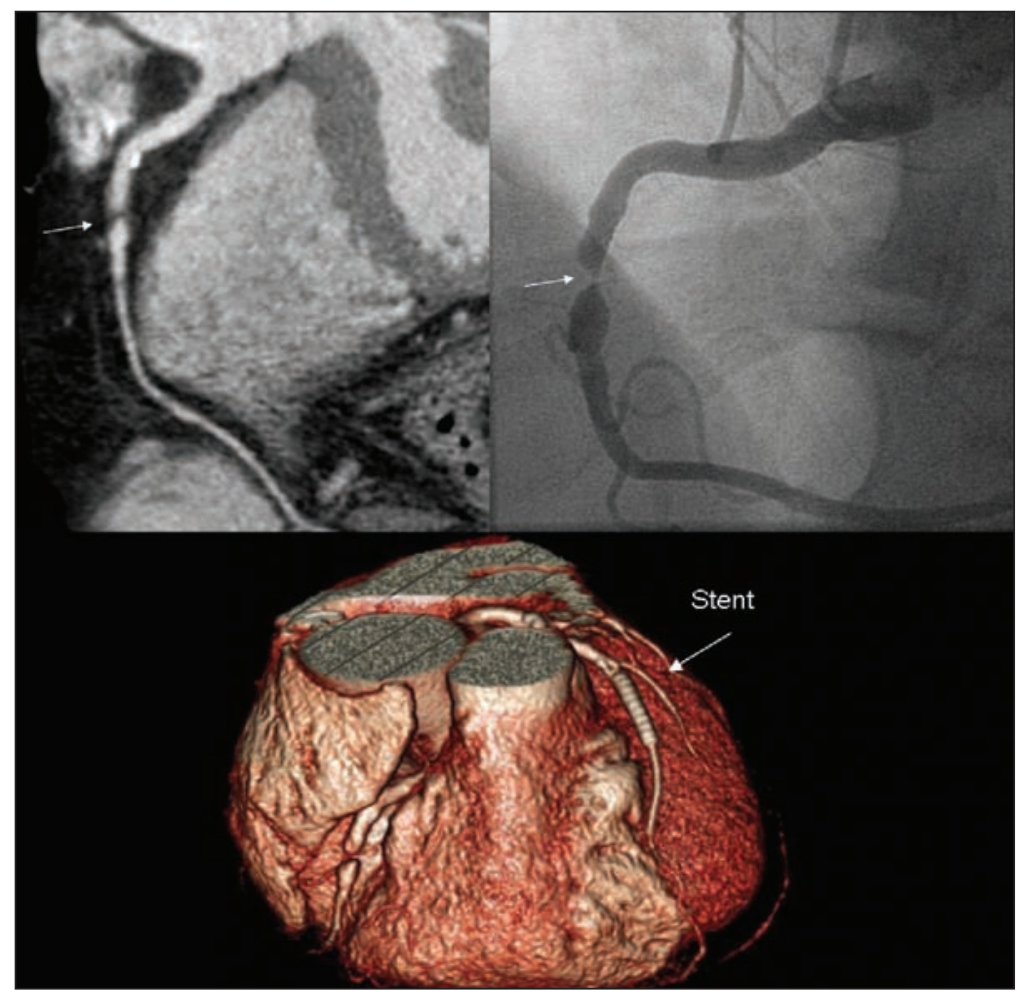

Fig. 5: This patient experienced recurrent angina a year after undergoing percutaneous coronary intervention $(\mathrm{PCl})$. Cardiac $\mathrm{CT}$ revealed a new critical stenosis (arrows) in the middle of the right coronary artery, which was confirmed by invasive angiography and subsequently treated with a second $\mathrm{PCl}$. The 3-dimensional reconstruction (bottom) shows the stent clearly.

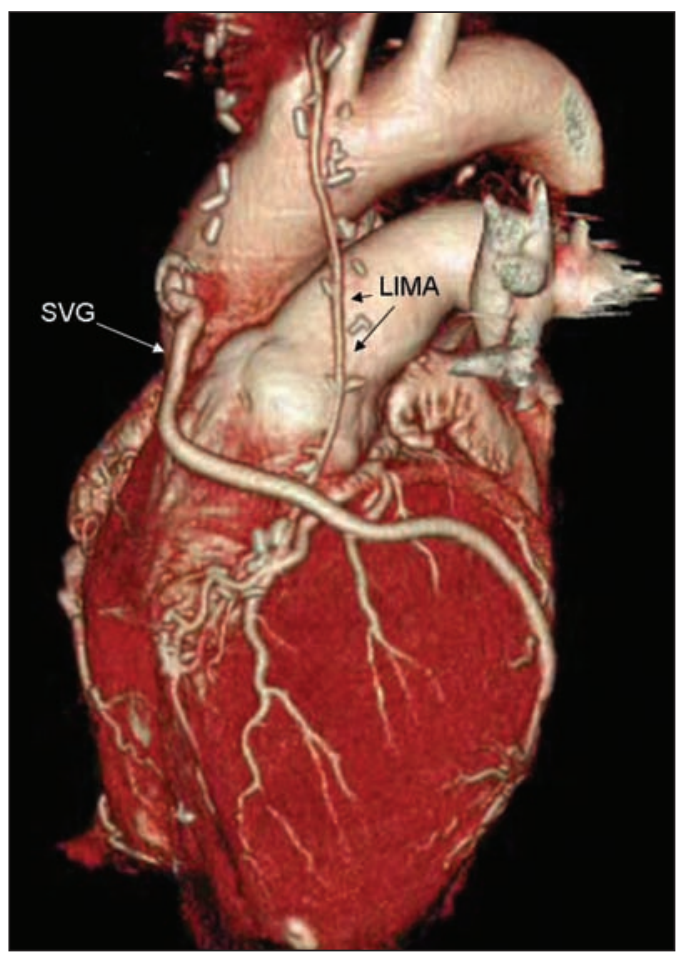

Fig. 6: A 3-dimensional reconstruction image showing patent bypass grafts in the left internal mammary artery (LIMA) and saphenous vein (SVG), by volume rendering. The entire data set for the image was acquired during a single 30 second breath-hold by the patient.

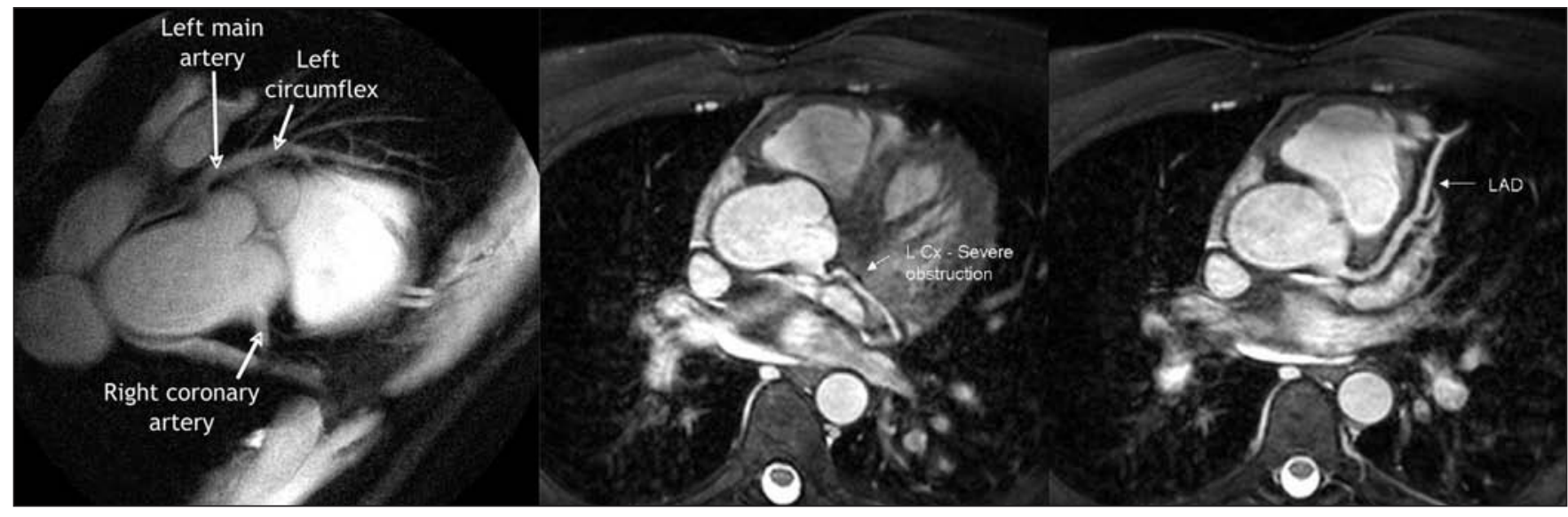

Fig. 7: MRIs of the heart of 1 patient. Left panel: the right coronary artery (showing proximal obstruction) and the left main and left anterior descending coronary arteries (no notable obstruction). Middle panel: the left circumflex (LCx) of the coronary artery, with a proximal lesion. Right panel: the left anterior descending artery (LAD), with no lesions visible.

This article has been peer reviewed.

From the Cardiovascular Research Institute, Medstar Research Institute, Medstar Health, Washington Hospital Center, Washington, DC.

Competing interests: None declared for Esteban Escolar, Guy Weigold and Anthon Fuisz. Neil Weissman has received speaker's fees from Boston Scientific.

Contributors: All authors made substantial contributions to the study's conception and design; the data acquisition, analysis and interpretation; and the drafting and critical revision of the article. All authors gave final approval of the version to be published.

\section{REFERENCES}

I. Arnett EN, Isner JM, Redwood CR, et al. Coronary artery narrowing in coronary heart disease: comparison of cineangiographic and necropsy findings. Ann Intern Med I979;9I:350-6.

2. Abizaid AS, Mintz GS, Abizaid A, et al. One-year follow-up after intravascular 
ultrasound assessment of moderate left main coronary artery disease in patients with ambiguous angiograms. J Am Coll Cardiol I999;34:707-I5

3. Ge J, Erbel R, Gerber T, et al. Intravascular ultrasound imaging of angiographically normal coronary arteries: a prospective study in vivo. Br Heart J I994;7I:572-8.

4. Mintz GS, Griffin J, Chuang YC, et al. Reproducibility of the intravascular ultrasound assessment of stent implantation in saphenous vein grafts. Am J Cardiol I995;75:1267-70.

5. Hausmann D, Erbel R, Alibelli-Chemarin MJ, et al. The safety of intracoronary ultrasound: a multicenter survey of 2207 examinations. Circulation I995;91:623-30.

6. Castagna MT, Mintz GS, Leiboff BO, et al. The contribution of "mechanical" problems to in-stent restenosis: an intravascular ultrasonographic analysis of Iogo consecutive in-stent restenosis lesions. Am Heart J 200I;I42:970-4.

7. Escolar E, Mintz GS, Hong MK, et al. Relation of intimal hyperplasia thickness to stent size in paclitaxel-coated stents. Am J Cardiol 2004;94:I96-8.

8. Hoffmann R, Mintz GS, Pichard AD, et al. Intimal hyperplasia thickness at followup is independent of stent size: a serial intravascular ultrasound study. Am J Car diol I998;82:II68-72.

9. Fujii K, Carlier SG, Mintz GS, et al. Stent underexpansion and residual reference segment stenosis are related to stent thrombosis after sirolimus-eluting stent implantation: an intravascular ultrasound study. J Am Coll Cardiol 2005;45:995-8.

Io. Cheneau E, Pichard AD, Satler LF, et al. Intravascular ultrasound stent area of sirolimus-eluting stents and its impact on late outcome. Am J Cardiol 2005;95: I240-2.

II. Schiele F, Meneveau N, Vuillemenot A, et al. The REStenosis after IvUs-guided STenting (RESIST) Study Group. Impact of intravascular ultrasound guidance in stent deployment on 6-month restenosis rate: a multicenter, randomized study comparing two strategies - with and without intravascular ultrasound guidance. J Am Coll Cardiol I998; 32:320-8.

I2. Schiele F, Meneveau N, Seronde MF, et al. Medical costs of intravascular ultrasound optimization of stent deployment: results of the multicenter randomized REStenosis after Intravascular ultrasound Stenting (RESIST) study. Int J Cardiovasc Intevent 2000;3:207-I3.

I3. Mudra H, di Mario C, de Jaegere P, et al. Randomized comparison of coronary stent implantation under ultrasound or angiographic guidance to reduce stent restenosis (OPTICUS study). Circulation 200I;I04:1343-9.

I4. Oemrawsingh PV, Mintz GS, Schalij MJ, et al. Intravascular ultrasound guidance improves angiographic and clinical outcome of stent implantation for long coronary artery stenoses: final results of a randomized comparison with angiographic guidance (TULIP study). Circulation 2003;107:62-7.

I5. Glagov S, Weisenberg E, Zarins CK, et al. Compensatory enlargement of human atherosclerotic coronary arteries. N EngI J Med I986;316:I37I-5.

I6. Topol EJ, Nissen SE. Our preoccupation with coronary luminology: the dissociation between clinical and angiographic findings in ischemic heart disease. Circulation I995;92:2333-42.

17. Erbel R, Ge A, Bockisch A, et al. Value of intracoronary ultrasound and Doppler in the differentiation of angiographically normal coronary arteries: a prospective study in patients with angina pectoris. Eur Heart J I996;17:880-9.

I8. Virmani R, Kolodgie FD, Burke AP, et al. Lessons from sudden coronary death: a comprehensive morphological classification scheme for atherosclerotic lesions. Arterioscler Thromb Vasc Biol 2000;20:1262-75.

I9. Jang IK, Tearney GJ, MacNeill B, et al. In vivo characterization of coronary atherosclerotic plaque by use of optical coherence tomography. Circulation 2005; III I55I-5.

20. Chiesa G, Monteggia E, Marchesi M, et al. Recombinant apolipoprotein A-I $\mathrm{I}_{\text {Milano }}$ infusion into rabbit carotid artery rapidly removes lipid from fatty streaks. Circ Res 2002;90:974-80.

2I. Juergens KU, Grude M, Maintz D, et al. Multi-detector row CT of left ventricular function with dedicated analysis software versus MR imaging: initial experience. Radiology 2004;230:403-10.

22. Koch K, Oellig F, Oberholzer K, et al. Assessment of right ventricular function by I6-detector-row CT: comparison with magnetic resonance imaging. Eur Radiol 2005; 15:312-8.

23. Nieman K, Cademartiri F, Lemos PA, et al. Reliable noninvasive coronary angiography with fast submillimeter multislice spiral computed tomography. Circulation 2002;106:205I-4.

24. Ropers D, Baum U, Pohle K, et al. Detection of coronary artery stenoses with thinslice multi-detector row spiral computed tomography and multiplanar reconstruction. Circulation 2003;107:664-6.
25. Hoffmann U, Moselewski F, Cury, RC, et al. Predictive value of I6-slice multidetector spiral computed tomography to detect significant obstructive coronary artery disease in patients at high risk for coronary artery disease patient versus segmentbased analysis. Circulation 2004;110:2638-43.

26. Hoffmann $\mathrm{MH}$, Shi $\mathrm{H}$, Schmitz BL, et al. Noninvasive coronary angiography with multislice computed tomography. JAMA 2005;293:247I-8.

27. Kuettner A, Beck T, Drosch T, et al. Diagnostic accuracy of noninvasive coronary imaging using I6-detector slice spiral computed tomography with I $88 \mathrm{~ms}$ temporal resolution. J Am Coll Cardiol 2005;45:123-7.

28. Leschka S, Alkadhi H, Plass A, et al. Accuracy of MSCT coronary angiography with 64-slice technology: first experience. Eur Heart J 2005;I5:I482-7.

29. Mollet NR, Cademartiri F, Krestin GP, et al. Improved diagnostic accuracy with I6row multi-slice computed tomography coronary angiography. J Am Coll Cardiol 2005;45:128-32.

30. Raff GL, Gallagher MJ, O'Neill WW, et al. Diagnostic accuracy of noninvasive coronary angiography using 64-slice spiral computed tomography. J Am Coll Cardiol 2005;46:552-7.

31. Martuscelli E, Romagnoli A, D'Eliseo A, et al. Evaluation of venous and arterial conduit patency with I6-slice spiral computed tomography. Circulation 2004;III: 3234-8.

32. Schlosser T, Konorza T, Hunold P, et al. Noninvasive visualization of coronary artery bypass grafts using i6-detector row computed tomography. J Am Coll Cardio 2004;44:1224-9.

33. Aviram G, Sharony R, Kramer A, et al. Modification of surgical planning based on cardiac multidetector computed tomography in reoperative heart surgery. Ann Thorac Surg 2005;79:589-95.

34. Burke AP, Taylor A, Farb A, et al. Coronary calcification: insights from sudden coronary death victims. $Z$ Kardiol 2000;89(Suppl 2):49-53.

35. Schmermund A, Schwartz RS, Adamzik M, et al. Coronary atherosclerosis in unheralded sudden coronary death under age fifty: histo-pathologic comparison with "healthy" subjects dying out of hospital. Atherosclerosis 2001;155:499-508.

36. Schmermund A, Erbel R. Unstable coronary plaque and its relation to coronary calcium. Circulation 200I; 104:I682-7.

37. Goldstein JA, Demetriou D, Grines CL, et al. Multiple complex coronary plaques in patients with acute myocardial infarction. N EnglJMed 2000;343:915-22.

38. Asakura M, Ueda Y, Yamaguchi O, et al. Kodama Extensive development of vulnerable plaques as a pan-coronary process in patients with myocardial infarction: an angioscopic study. J Am Coll Cardiol 2001;37:1284-8.

39. Shaw LJ, Raggi P, Schisterman E, et al. Prognostic value of cardiac risk factors and coronary artery calcium screening for all-cause mortality. Radiology 2003;228: 826-33.

40. Arad Y, Goodman KJ, Roth M, et al. D. Coronary calcification, coronary disease risk factors, C-reactive protein, and atherosclerotic cardiovascular disease events: the St. Francis Heart Study. J Am Coll Cardiol 2005;46:158-65.

4I. Greenland P, Abrams J, Aurigemma GP, et al; Writing Group III. Prevention Conference $\mathrm{V}$. Beyond secondary prevention: identifying the high-risk patient for primary prevention. Noninvasive tests of atherosclerotic burden. Circulation 2000; IOI:Ei6-22.

42. Greenland P, Smith SC Jr, Grundy SM. Improving coronary heart disease risk assessment in asymptomatic people: role of traditional risk factors and noninvasive cardiovascular tests. Circulation 2001;104:1863-7.

43. Paulin S, von Schulthess GK, Fossel E, et al. MR imaging of the aortic root and proximal coronary arteries. AJR Am J Roentgenol I987;148:665-70.

44. Rehwald WG, Chen EL, Kim RJ, et al. Noninvasive cineangiography by magnetic resonance global coherent free precession. Nat Med 2004;10:545-9.

45. Kim WY, Danias PG, Stuber M, et al. Coronary magnetic resonance angiography for the detection of coronary stenoses. N Engl J Med 2001;345:1863-9.

46. Spuentrup E, Buecker A, Katoh M, et al. Molecular magnetic resonance imaging of coronary thrombosis and pulmonary emboli with a novel fibrin-targeted contrast agent. Circulation 2005; III:1377-82.

47. Delikatny EJ, Poptani H. MR techniques for in vivo molecular and cellular imaging. Radiol Clin North Am 2005;43:205-20.

Correspondence to: Dr. Neil J. Weissman, roo Irving St. NW, Suite EB 5123, Washington DC 20010-2975; fax 202 877-0206; neil.j.weissman@medstar.net 